\title{
Public Spending Management and Macroeconomic Interdependence
}

\author{
Giovanni Ganelli, Trinity College Dublin*
}

September 2003

\begin{abstract}
This paper studies the international macroeconomic effects of microeconomic measures, aimed at improving the efficiency of public spending management by increasing the price-elasticity of public consumption. In order to do this, we develop a New Open Economy Macroeconomics (NOEM) model in which the elasticity of substitution between differentiated goods in public consumption is different from the one in private consumption and the optimal mark-up is endogenous. This allows us to disentangle the international effects of structural reforms that improve the efficiency of spending in the public sector. We find that such policies can significantly affect the macroeconomic interdependence pattern that follows asymmetric fiscal shocks. In welfare terms, we find that the countries with a larger government sector have an incentive to promote global "public competition policies".
\end{abstract}

Keywords: public competition policies; macroeconomic interdependence; government spending.

JEL Codes: E62; F41; H11

\footnotetext{
${ }^{*}$ Correspondence: Department of Economics and Institute for International Integration Studies, Trinity College Dublin, Dublin 2, IRELAND. Email: ganellig@tcd.ie Tel.: +353(0)1-6083227. Fax: +353-(0)1-6083939.
} 
This work is part of a research network on 'The Analysis of International Capital Markets: Understanding Europe's Role in the Global Economy', funded by the European Commission under the Research Training Network Programme (Contract No. HPRN-CT-1999-00067). The usual disclaimer applies. 


\section{Introduction}

The way in which governments manage public spending at a microeconomic level can have macroeconomic implications. The goal of this paper is to study how structural policies, aimed at improving the efficiency of public spending, can change the positive and normative interdependence pattern that follows an asymmetric fiscal shock. In our analysis, by "improving efficiency" we mean the process of reducing the degree of monopoly enjoyed by firms selling goods and services to the government, and therefore of bringing their prices closer to marginal costs.

Many of the structural measures that governments introduce in order to achieve this goal can be captured, in a stylized model, by an increase in the price elasticity of demand of government expenditure. For example, after public spending went out of control in the UK in the late 1970s, the government switched from planning its spending in real terms (or "volume" planning) to planning it in value terms (or "nominal" planning). Such a shift can be modeled as a change in the price elasticity of government spending from zero to one. ${ }^{1}$

More generally, an increase in the price-elasticity of public demand can capture the effects of the implementation of other measures aimed at improving the efficiency of public spending. Examples of those measures are policies that oblige government departments to put the provision of certain goods and services out to tender, making private firms bid competitively to provide them. In the UK, the Thatcher government introduced numerous measures of this sort in the 1980s. A more recent example can be found in the US, where the role of private managed care organizations in the government Medicare and Medicaid programs is increasing dramatically. ${ }^{2}$

However, most existing macroeconomic models are, for the reasons that we will explain below, not well equipped to capture the effects of the policies that we want to study. The standard way in which most macroeconomic

\footnotetext{
${ }^{1}$ See Dixon and Rankin (1995), pp. 52-53, for a discussion.

${ }^{2}$ It is now estimated that such organizations provide medical services for more that one third of the 75 millions of beneficiaries of the two programs (Duggan 2002).
} 
models deal with government spending is to treat it as exogenous in real terms. This is true, for example, both in Keynesian ad hoc models and in the Real Business Cycle (RBC) tradition. Those kinds of models usually do not differentiate between the various goods that enter public consumption, therefore implicitly assuming that government demand for an individual good type is also exogenous in real terms. ${ }^{3}$ In microeconomic terms, these assumptions imply a zero price-elasticity of government demand.

The New Open Economy Macroeconomics (NOEM) literature, by explicitly modelling imperfect competition, allows a differentiation between the individual goods that enter public consumption. ${ }^{4}$ A limitation of the analysis carried out so far using NOEM models is, however, the fact that aggregate public consumption is built in the same way as private consumption, with the same elasticity of substitution between the differentiated goods produced in the economy. ${ }^{5}$ This rules out the possibility of analysing the effects of structural government policies that can alter the elasticity of substitution in public consumption without affecting the private elasticity.

In this paper we fill in this gap in the literature, developing a NOEM model in which the private and public elasticities can be disentangled. This allows us to analyse the positive and normative implications for asymmetric fiscal shocks of policies that increase the public elasticity of substitution.

Throughout the paper we will refer to policies that imply an increase in the elasticity of substitution of government demand as "public competition policies". This semantic convention rests on the fact that, as we have stressed above, such policies reduce the degree of monopoly enjoyed by private producers when dealing with the government. It is important to stress again that it would not be possible to capture the effects of such policies in a standard NOEM model that does not differentiate between the private and the public elasticities. Obviously, in that case, a change in the public elasticity

\footnotetext{
${ }^{3}$ A noteworthy exception is Finn (1998), who differentiates between government's employment and goods purchases.

${ }^{4}$ The supply side of the NOEM framework can be regarded as an extension of the closed-economy, static model presented by Blanchard and Kiyotaki (1987).

${ }^{5}$ For a survey of how fiscal policy has been introduced in the NOEM literature, see Ganelli and Lane (2002), section 4.
} 
would mean that the private elasticity is changing as well, and it would not be possible to interpret the exercises on which we focus as consequences of structural reforms in the government sector.

Our model shows that such policies imply, on the positive side, a reduction of the negative effect on relative consumption that usually follows a balanced-budget asymmetric fiscal shock. As standard in the NOEM framework, the country that implements a balanced-budget fiscal shock still loses, in terms of consumption, relative to the foreign country, but the international consumption gap can be reduced by the implementation of public competition policies. An increase in the elasticity of substitution also implies a larger expenditure switching effect. The short-run increase in relative output that follows a fiscal shock can therefore be quantitatively bigger, when public competition policies are implemented, even with a less depreciated exchange rate.

On the normative side, our analysis shows that the implementation of public competition policies raises the level of welfare of the country with a larger public sector at foreign expenses.

The structure of the paper is as follows: next section introduces the model, section 3 investigates the positive effects of public competition policies, using numerical solutions based on the reduced forms derived from a linearized version of the model, section 4 discusses some welfare results; section 5 concludes.

\section{The Model}

We use a standard NOEM model (similar to the one developed by Obstfeld and Rogoff 1995, 1996), modified to allow for an elasticity of substitution in public consumption different from the one in private consumption. There are two countries in the world that we label Home and Foreign. The world population is normalized to one. Home agents are on the interval $[0, n]$, foreign agents on the interval $(n, 1]$. Since we assume perfect symmetry in preferences and parameters, we will only present the equations for the domestic economy. 


\subsection{Private Agents}

The domestic representative agent gains utility from domestic private consumption, real balances and leisure. The agents' optimization problem is therefore the maximization of the intertemporal utility function

$$
U_{t}^{j}=\sum_{s=t}^{\infty} \beta^{s-t}\left[\log \left(C_{s}\right)+\chi \log \frac{M_{s}}{P_{s}}-\frac{k}{2} L_{s}^{2}\right]
$$

subject to the budget constraint

$$
B_{t+1}+\frac{M_{t}}{P_{t}}=\left(1+r_{t}\right) B_{t}+\frac{M_{t-1}}{P_{t}}+\frac{W_{t}}{P_{t}} L_{t}+\frac{\Pi_{t}}{P_{t}}-C_{t}-\tau_{t}
$$

where $0<\beta<1$ is the discount factor, all the parameters are positive and the last term in the utility function captures the disutility, in terms of reduced leisure, of supplying an amount of labour equal to $L$. The only internationally traded bond is a riskless real bond denominated in terms of the composite consumption good, that we denote with $B, r_{t}$ is the real interest rate on this bond between $t-1$ and $t$. $M_{t-1}$ denotes nominal money balances held at the beginning of period $t .{ }^{6}$ Agents also supply labour in a perfectly competitive labour market, receive profits shares from domestic firms $\frac{\Pi_{t}}{P_{t}}$, that we assume to be uniformly distributed, and pay lump-sum taxes $\tau_{t}$.

The private consumption index aggregates across the differentiated goods produced by all firms in the economy, both at home and abroad. Firms enjoy a certain degree of monopolistic competition when dealing with private consumers, specified by the magnitude of the parameter $\theta>1$. Denoting with $z$ a generic representative firm, with $c(z)$ the consumption of the differentiated output of this firm by the representative agent and with $p(z)$ the domestic currency price of this output, the aggregate private consumption index and the corresponding price index take the following forms

$$
C=\left[\int_{0}^{1} c(z)^{\frac{\theta-1}{\theta}} d z\right]^{\frac{\theta}{\theta-1}}
$$

\footnotetext{
${ }^{6}$ Note that we adopt Obstfeld and Rogoff (1996) timing convention, $M_{t}$ therefore denotes money between period $t$ and period $t+1$, while $B_{t}$ denotes bonds between period $t-1$ and $t$.
} 


$$
P=\left[\int_{0}^{1} p(z)^{(1-\theta)} d z\right]^{\frac{1}{1-\theta}}
$$

\subsection{The Government}

As already stressed above, the main innovation of our model is that of allowing the elasticity of public spending to be different from the elasticity of private spending. In order to do this, we introduce a government whose consumption in real terms is an aggregate of all the differentiated goods produced in the economy, with a certain elasticity of substitution $\eta$ that, unlike in previous NOEM models, is not restricted to be equal to $\theta$. The Home government aggregate consumption and the corresponding government spending price index are therefore given by

$$
\begin{aligned}
G & =\left[\int_{0}^{1} g(z)^{\frac{\eta-1}{\eta}} d z\right]^{\frac{\eta}{\eta-1}} \\
P_{G} & =\left[\int_{0}^{1} p(z)^{(1-\eta)} d z\right]^{\frac{1}{1-\eta}}
\end{aligned}
$$

The government follows a balanced-budget rule all the time. ${ }^{7}$ We also rule out the possibility of seigniorage, implying that in every period $G_{t}=\tau_{t}$. The preferences and behavior of the foreign government are perfectly symmetric.

It is worth noticing two implications of our assumption of perfect symmetry. The first is that both governments consume all differentiated goods, regardless of their place of production, therefore eliminating the possibility of home bias in public spending. The second is that the parameter $\eta$ is the same for both countries. This means that the public competition policies (i.e. the policies of increasing $\eta$ ) that we will consider should be thought of as global policies coordinated internationally, rather than implemented asymmetrically by one country. Introducing home bias in government spending and considering country-specific public competition policies would undoubtedly be of interest for future research, but we abstract from this possibilities in this paper.

\footnotetext{
${ }^{7}$ Because Ricardian Equivalence holds in the model, government debt would be redundant.
} 


\section{$2.3 \quad$ Firms}

We assume the existence of a continuous of measure one of firms in the world, $n$ of which located in the Home country and $1-n$ in the Foreign country. We also assume that the law of one price (LOOP) holds, implying

$$
p_{t}(z)=E_{t} p_{t}^{*}(z)
$$

where $\mathrm{E}$ is the nominal exchange rate, defined as the price of the foreign currency in terms of the domestic currency and $p_{t}^{*}(z)$ is the foreign currency price of good $z$. The LOOP assumption and the definition of the price indexes imply that also the purchasing power parity (PPP) holds, both for private and for public consumption prices

$$
\begin{aligned}
P_{t} & =E_{t} P_{t}^{*} \\
P_{G t} & =E_{t} P_{G t}^{*}
\end{aligned}
$$

The fact that the LOOP and the PPP hold, together with the specification of the private and public consumption indexes (equations 3 and 5), imply that the demand for the output of the representative firm $z$ is given by

$$
Y_{t}(z)=\left[\frac{p_{t}(z)}{P_{t}}\right]^{-\theta} C_{t}^{W}+\left[\frac{p_{t}(z)}{P_{G t}}\right]^{-\eta} G_{t}^{W}
$$

where the superscript $W$ denotes world aggregates. ${ }^{8}$

Finally, we assume that for each firm output is simply equal to labour input according to the production function

$$
Y_{t}(z)=L_{t}(z)
$$

\subsection{Current Account Equations}

The model is completed by a short-run and a long-run version of the current account equations, where all the variables are expressed in terms of the composite consumption good

\footnotetext{
${ }^{8}$ Since the $n$ domestic firms behave symmetrically, equation (7) also gives per-capita output in the domestic country.
} 


$$
\begin{aligned}
B_{t+1}-B_{t} & =r_{t} B_{t}+\frac{p_{t}(h) Y_{t}}{P_{t}}-C_{t}-\frac{P_{G t}}{P_{t}} G_{t} \\
\widehat{C} & =\delta \widehat{B}+\frac{\widehat{p}(h) \widehat{Y}}{\widehat{P}}-\frac{\widehat{P}_{G}}{\widehat{P}} \widehat{G}
\end{aligned}
$$

Equation (9) is valid in the short run (when the shock hits), while equation (10) is only valid across steady states.

\subsection{Optimality Conditions}

Using standard techniques, it is possible to show that the first order conditions for the private agent's maximization problem are given by

$$
\begin{aligned}
C_{t+1} & =C_{t}\left[\beta\left(1+r_{t+1}\right)\right] \\
\frac{M_{t}}{P_{t}} & =\frac{\chi\left(1+i_{t+1}\right)}{i_{t+1}} C_{t} \\
k L_{t} & =\frac{1}{C_{t}} \frac{W_{t}}{P_{t}}
\end{aligned}
$$

where $i_{t+1}$ is the nominal interest rate between $t$ and $t+1$.

Equations (11) to (13) are respectively a consumption Euler equation, a money demand equation and a labour-leisure trade off equation, that equates the marginal utility of the real wage to the marginal disutility of supplying an additional unit of labour.

While the above equations are standard in microfounded models, the profit-maximization condition of the representative firm yields a less standard mark-up formula

$$
p_{t}(z)=W_{t} \frac{\theta Y_{t}^{d, p}(z)+\eta Y_{t}^{d, g}(z)}{(\theta-1) Y_{t}^{d, p}(z)+(\eta-1) Y_{t}^{d, g}(z)}
$$

where $Y_{t}^{d, p}(z)$ and $Y_{t}^{d, g}(z)$ are respectively the total private and public demands for the representative good $z$, defined as

$$
\begin{aligned}
Y_{t}^{d, p}(z) & =\left[\frac{p_{t}(z)}{P_{t}}\right]^{-\theta} C_{t}^{W} \\
Y_{t}^{d, g}(z) & =\left[\frac{p_{t}(z)}{P_{t}}\right]^{-\theta} G_{t}^{W}
\end{aligned}
$$


It should be noticed that equation (14) reproduces the usual mark-up of prices on wages, equal to $\frac{\theta}{(\theta-1)}$, in the special cases in which the public elasticity is equal to the private elasticity $(\eta=\theta)$ or world government spending is zero. In the more general case, the mark-up is endogenous and, in absence of price rigidities, private firms will set prices above marginal costs taking in to account both the private and the public elasticities, as well as the ratio of public to private demand for their products. ${ }^{9}$ An increase in $\eta$, by reducing the monopoly power of firms, reduce the wedge between prices and wages, therefore generating lower profits.

However, since, following Obstfeld and Rogoff $(1995,1996)$ we will assume one-period price rigidity in the producers' currency, $p(z)$ will be pre-set in the period in which a fiscal shock hits. Prices will be set according to equation (14) only in the period after the shock (that we define as the long-run), when they are free to adjust to their flexible-price values. The effects of the endogenous mark up, nonetheless, will be reflected in short-run variables due to the presence of rational expectations.

\subsection{The Initial Steady-State}

The numerical solutions that we will present in section 3 are based on reduced forms derived from a log-linear approximation of the model around a symmetric steady-state. To be able to capture the effects of a different public-spending elasticity of substitution in the linearized equations, it is necessary to log-linearize the model starting from a non-zero government spending position. ${ }^{10}$ In order to preserve symmetry, we consider an initial steady state in which the positive level of public spending is the same in both

\footnotetext{
${ }^{9}$ Previous research has shown that an endogenous mark-up can also be derived either by explicitly modeling intra-industry collusion (Rotemberg and Woodford 1992) or by assuming that the elasticity of substitution across goods in consumption differs from that in production (Gali 1994).

${ }^{10}$ Starting from a non-zero government spending steady-state value is also a desirable feature of the analysis in itself, not present in previous NOEM contributions, such as Obstfeld and Rogoff $(1995,1996)$ and Ganelli (2003). The fact that we start from a nonzero public spending steady state implies that the ratio of public to private spending in the initial steady state enters the log-linearized equations.
} 
countries and initial net foreign assets are zero in both countries. Denoting the initial pre-shock values with the subscript ${ }_{S S}$, in such a steady state the following relationships hold: $G_{S S}=G_{S S}^{*}=G_{S S}^{W}>0, B_{S S}=B_{S S}^{*}=0$, $p_{S S}(z)=P_{S S}=P_{G_{S S}}, p_{S S}^{*}(z)=P_{S S}^{*}=P_{G S S}^{*}, C_{S S}=C_{S S}^{*}=C_{S S}^{W}$ and $Y_{S S}=Y_{S S}^{*}=Y_{S S}^{W}{ }^{11}$ Steady-state levels of the main variables are given by

$$
\begin{gathered}
\delta=r_{0}=\frac{1-\beta}{\beta} \\
\frac{W_{S S}}{P_{S S}}=\frac{\theta-1+(\eta-1) \lambda}{\theta+\eta \lambda} \\
Y_{S S}=\left\{\frac{(1+\lambda)[(\theta-1)+(\eta-1) \lambda]}{k(\theta+\eta \lambda)}\right\}^{\frac{1}{2}} \\
C_{S S}=\frac{Y_{S S}}{1+\lambda}
\end{gathered}
$$

and

$$
\frac{M_{S S}}{P_{S S}}=\chi \frac{1+\delta}{\delta} C_{S S}
$$

where $\lambda=\frac{G_{S S}}{C_{S S}}$ is the ratio of public to private spending in the initial steady state. The steady-state values of $r, C, Y$ and $M / P$ coincide with the ones used by Obstfeld and Rogoff $(1995,1996)$ when $\theta=\eta$ and $G_{S S}=0$. Increases in $\theta$ and $\eta$, by reducing the degree of monopolistic distortion in the economy, raise the steady-state levels of output and consumption.

\subsection{Log-linearization}

The log-linearized version of the domestic economy is presented in Table 1. Log-deviations in the period in which the shock hits (the short run), are denoted by lower cases with a tilde, for example: $\widetilde{c}=\frac{d C}{C_{S S}} \simeq \frac{C-C_{S S}}{C_{S S}}$. Lower cases with a hat denote long-run variables, i.e. log deviations in the period

\footnotetext{
${ }^{11} G, C$, and $Y$ are expressed in per-capita terms. Given our assumption of symmetry, world variables can be derived by multiplying the home variable by $n$, the foreign by $1-n$ and adding the results. For example $Y^{W}=n Y+(1-n) Y^{*}$. Since world population is one, aggregate and per-capita world variables coincide.
} 
after the one in which the shock hits, in which the economy is free to adjust to its new, flexible-price steady state. The variables $\widetilde{p}(h)$ and $\widetilde{p}^{*}(f)$ denote, respectively, the short-run log-deviations of the prices set by a representative domestic and foreign firm. The hypothesis of one period pre-set prices in the producers' currency means that we can set $\widetilde{p}(h)=\widetilde{p}^{*}(f)=0$ in all the equations listed in Table 1 and in their analogous for the foreign economy. Since the initial steady-state of net foreign assets is zero, $\widehat{b}$ is defined as $\widehat{b}=$ $\frac{d B}{C_{S S}} \cdot 12$

In Table $1 \psi_{1}, \psi_{2}$ and $\psi_{3}$ are composite parameters, that are functions of $\theta, \eta$ and $\lambda$ as defined in the appendix. Log-linearization around a symmetric initial steady-state in which the law of one price holds implies that the log-linearized versions of the private and of the public price indexes are equivalent, as shown in equation (15). Equations (16) to (24) are respectively (log-linearized versions of) the world demand function for the representative differentiated good, the Euler equation, short-run and long-run money demand equations, the labor-leisure trade off equation, short-run and long-run current account equations, the optimal pricing rule (equation 14) and the PPP equation. Because of the short-run price rigidity, equation (20) and (23) are only valid in the long run.

\footnotetext{
${ }^{12}$ Notice that, as in Obstfeld and Rogoff $(1995,1996)$, the price adjustment that we are assuming implies that whatever value of net foreign assets arises at the end of the first period becomes the new steady-state level from the period after the shock onwards.
} 
Table 1. The log linearized domestic economy

$$
\begin{aligned}
\widetilde{p} & =\widetilde{p}_{G}=n \widetilde{p}(h)+(1-n)\left[\widetilde{e}+\widetilde{p}^{*}(f)\right] \\
\widetilde{y} & =\frac{\theta}{1+\lambda} \widetilde{c}^{w}+\frac{\lambda}{1+\lambda} \widetilde{g}^{w}+\frac{\theta}{1+\lambda}\left[\widetilde{p}-\widetilde{p}(h]+\frac{\lambda}{1+\lambda} \eta\left[\widetilde{p}_{G}-\widetilde{p}(h(16)\right.\right. \\
\widehat{c} & =\widetilde{c}+\frac{\delta}{1+\delta} \widetilde{r} \\
\widetilde{m}-\widetilde{p} & =\widetilde{c}+-\frac{\widetilde{r}}{1+\delta}-\frac{\widehat{p}-\widetilde{p}}{\delta} \\
\widehat{m}-\widehat{p} & =\widehat{c} \\
\widehat{l} & =\widehat{y}=\widehat{w}-\widehat{c}-\widehat{p} \\
\widehat{b} & =(1+\lambda) \widetilde{y}-(1+\lambda) \widetilde{p}-\widetilde{c}-\lambda \widetilde{g} \\
\widehat{c} & =\delta \widehat{b}+(1+\lambda) \widehat{y}+(1+\lambda) \widehat{p}(h)-(1+\lambda) \widehat{p}-\lambda \widehat{g} \\
\widehat{w}-\widehat{p}(z) & =\psi_{1}(\theta, \eta, \lambda) \widehat{c}^{W}+\psi_{2}(\theta, \eta, \lambda) \widehat{g} W+\psi_{3}(\theta, \eta, \lambda)[\widehat{p}-\widehat{p}(h)] \\
\widetilde{e} & =\widetilde{p}-\widetilde{p}^{*}
\end{aligned}
$$

Using the equations contained in Table 1 and the analogous expressions for the foreign economy, we derived reduced forms for endogenous variables as functions of fiscal shocks and of the parameters of the model. The reduced forms have then been used to provide the numerical solutions reported in section 3. Given our focus on the effects of public competition policies in presence of asymmetric fiscal shocks, in our experiments we always set money shocks to zero.

\section{The Effects of Public Competition Policies}

In this section we study how public competition policies affect the positive and normative results of the model in presence of asymmetric fiscal shocks. In order to do so, we provide some numerical results based on the reduced forms of the log-linearized model. Given the simple dynamics of the model, the economy reaches the new steady state in the period after the shock. In 3.2 we show the response of domestic and foreign macroeconomic variables 
to an asymmetric fiscal shock, in which the log-deviation of domestic government spending is set to 1 , and the one of foreign spending is set to 0 . All shocks considered are permanent balanced-budget expansions. We compare the responses of the economy for different values of $\eta$. We interpret an increase in $\eta$ as the implementation of global public competition policies.

Since our model is a very stylized ones, our numerical solutions should not be read as attempts to reproduce realistic quantitative dynamics that can be observed in real data. The parametrization of the reduced forms that we provide is, nonetheless, useful in order to illustrate the qualitative mechanisms at work in the model.

\subsection{Calibration of the Parameters}

In the benchmark calibration, we follow Sutherland (1996) in setting $\beta=$ $1 / 1.05$ and $\theta=6$. The chosen value of $\beta$ is consistent with a long-run real interest rate of about 5 percent. We consider the case of symmetric countries, therefore setting $n=.5$. The ratio of public to private consumption in the initial steady state is set at $\lambda=.23$. This value is equal to the ratio of average government consumption expenditure to personal consumption expenditure in the US, calculated using quarterly data for the period 1987:1 to $2003: 1 .^{13}$

In 3.2 we report the responses of the main macroeconomic variables to an asymmetric fiscal shock for the above parametrization, for different values of $\eta$ ranging from 1.1 to $100 .{ }^{14}$ Since the long-run is reached in the period after the shock, the graphs report the deviation from the initial steady state in the short run (when the shock hits) and in the following period, in which the economy reaches the new steady state.

In 3.4 we discuss some sensitivity experiments, that we carried out in order to check the robustness of our results to changes in the chosen parametrization.

\footnotetext{
${ }^{13}$ The source is the Bureau of Economic Analysis, National Accounts Data (available online at http://www.bea.doc.gov/bea/dn1.html).

${ }^{14} \mathrm{~A}$ necessary condition for the government consumption index to be well defined is $\eta>1$ (see equation 5 ).
} 


\subsection{Numerical Solutions}

\subsection{Positive Effects}

Figures 1 to 6 present the responses of domestic and foreign consumption, domestic and foreign output, the exchange rate and net foreign assets held by domestic residents to an asymmetric domestic fiscal shock, for different values of $\eta$.

Comparing Figures 1 and 2, it is clear that our model preserves a standard NOEM result, even when the public and the private elasticities are allowed to differ: in the short-run, the country that implements a balanced-budget fiscal expansion loses, in terms of relative private consumption, compared to the other country. ${ }^{15}$ In the case of a domestic expansion, this happens through a fall in domestic consumption and an increase in foreign.

A novel result of our model is that an increase in the elasticity of substitution of government demand reduces the fall in relative private consumption. In the short run this happens through both a smaller fall of domestic consumption and a smaller increase in foreign. Foreign consumption is reduced by an increase in $\eta$ both in the short and in the long run, with a more pronounced reduction in the flexible price periods. The response of domestic consumption is reduced in the long run, but becomes less negative in the short run, as a consequence of an increase in $\eta$. Although individual countries consumption profiles are tilted both by the fiscal shock and by changes in the government spending elasticity, these changes are consistent with the result of permanent effects on relative consumption, typical of NOEM models like the one we are using. ${ }^{16}$

The main mechanism at work behind the result that an increase in the elasticity of public demand reduces the fall in relative consumption is related to the increase in the degree of competition in the world economy brought about by such a policy, as we explain in what follows.

The standard reason for the fall in relative consumption in a NOEM model

\footnotetext{
${ }^{15}$ See Ganelli and Lane (2002), p.16.

${ }^{16}$ Formally, we have $\widetilde{c}-\widetilde{c}^{*}=\widehat{c}-\widehat{c}^{*}$, this can be proved using the domestic and foreign log-linearized Euler equations, that are not affected by changes in $\eta$.
} 
is that domestic residents are made poorer by the higher lump-sum taxes necessary to finance the increase in spending, while foreigners are better off because they get all the benefits of the policy, i.e. the positive stimulation of demand, without having to bear extra tax costs. An increase in $\eta$ reduces the degree of mark-up at all horizons, lowering firms' profit, that are redistributed to consumers as shares. This policy, therefore, also diminishes the benefits deriving from a fiscal expansion in terms of increased lifetime wealth deriving form higher redistributed profit shares. This effect contributes to reducing the asymmetry in benefits between domestic and foreign residents, generated by a domestic expansion. The reduction in this asymmetry explains why domestic relative consumption falls less as $\eta$ increases.

Although, as already stressed in section 2, prices are not set according to formula (14) in the short-run due to nominal stickiness, the reduction in profits associated with a higher $\eta$ in the flexible-price periods is also reflected in short-run decisions through the rational expectations mechanism.

Figures 3 and 4 illustrate the response of domestic and foreign output. In the case of output, unlike for consumption, short-run deviations from the initial steady state cannot be explained as consequences of wealth changes. This is due to the fact that, when prices are sticky, supply-side effects become irrelevant in the short-run. The short-run changes in output are therefore mainly due to the expenditure switching effect that follows the exchange rate adjustment, that we now discuss in order to shed some light on the output effects.

Using the Euler equations, the money demand equations and the purchasing power parity it is possible to show that the following relationship holds between short-run relative consumption and the exchange rate

$$
\widetilde{e}=-\left(\widetilde{c}-\widetilde{c}^{*}\right)
$$

Equation (25) illustrates the following mechanism (already pointed out by Obstfeld and Rogoff 1995, 1996): when relative consumption decreases, so does the domestic money demand compared to the foreign and, in order to restore the equilibrium in the money market, the exchange rate has to depreciate ( $\widetilde{e}$ has to go up). Figure 5 shows this exchange rate response for our 
benchmark parametrization. By subtracting the long-run foreign demand equation form its domestic counterpart (equation 19) and using the PPP, with zero money shocks, we derive $\left(\widehat{c}-\widehat{c}^{*}\right)=-\widehat{e}$. Combining the latter with equation (25) and with the result of permanent effects on relative consumption (see note 15), we can derive a no-overshooting result: the exchange rate jumps immediately to its more depreciated long-run value. While the latter result is standard in the NOEM framework, what matters most for our analysis are the effects of changes in $\eta$. Figure 5 illustrates how an increase in $\eta$, by reducing the fall in relative consumption, mitigates the nominal depreciation that follows a domestic fiscal shock.

The depreciation of the domestic currency and the subsequent expenditure switching effect can easily explain the results, shown in figures 3 and 4 , that the response of Home output is positive and the one of foreign output is negative in the short-run. The result that an increase in $\eta$ magnifies these effects (see figures 3 and 4), however, seems at odds with the fact that increasing $\eta$ also reduces the depreciation of the exchange rate. The contradiction between these two outcomes is, nonetheless, only apparent.

The key to understanding how an increase in $\eta$ can generate both a less depreciated exchange rate and a larger gap between domestic and foreign output is in noticing how the private and public elasticities $(\theta$ and $\eta)$, enter as differentiated parameters in the demand equation (16) and in its analogous expression for the foreign country. This implies that, subtracting the foreign analogous from equation (16), and making use of the PPP and of the one period price-rigidity assumption, we can derive the following short-run relationship between relative output and the exchange rate

$$
\widetilde{y}-\widetilde{y}^{*}=\frac{1}{1+\lambda}(\theta+\lambda \eta) \widetilde{e}
$$

As $\eta$ increases worldwide, due to the higher competitive pressure imposed on firms by the domestic and foreign governments, the degree of substitutability between goods purchased by the governments also increases. In absence of home bias in government expenditure, this means that, with a higher $\eta$, the same exchange rate variation can sustain larger shifts in relative demand for goods, and therefore in output. The latter effect is formally expressed by the 
fact that an increase in $\eta$ increases the response of $\widetilde{y}-\widetilde{y}^{*}$ to $\widetilde{e}$ in equation (26). Intuitively, this mechanism reconciles the effects of an increase in $\eta$ on the exchange rate (a reduced depreciation, i.e. a less pronounced increase in $\widetilde{e}$ ) and on short-run domestic and foreign output (a bigger expenditure switching effect), highlighted in Figures 3, 4 and 5.

Since prices are flexible in the long-run, long-run responses of output, unlike short-run ones, can be explained by supply-side factors. This means that the fall in domestic output and the increase in foreign output in the long-run, showed in Figures 3 and 4, can be interpreted as deriving respectively from an increase and a fall in the demand for leisure by domestic and foreign residents. An increase in $\eta$ magnifies those responses, pushing domestic agents to consume more leisure and foreigners to consume less. The decision to work less and enjoy more leisure is affected by the lifetime wealth of the individuals. It is therefore useful, in order to understand the above effects, to look at the response of net foreign assets, that links the short-run and long-run dynamics of the model.

Figure 6 reports the response of net foreign assets held by domestic residents to an asymmetric fiscal shock. As already mentioned above (see note 11 ), the one-period price stickiness implies that the value of net foreign assets that arises at the end of the first period becomes the new steady-state level from the period after the shock onwards. The increase in net foreign assets is a consequence of the fact that relative consumption falls and relative output increases in the short run. The effect of a higher $\eta$ in Figure 6 is to increase the amount of net foreign assets held by domestic residents. This is consistent with the short-run impact on relative output and consumption of a higher $\eta$, already stressed above. The Home country accumulates more assets and the Foreign country accumulates more liability as a consequence of the introduction of public competition policies, because domestic firms tend to increase their short-run output, in response to higher demand, as $\eta$ increases. ${ }^{17}$

The asymmetric wealth accumulation that follows domestic fiscal shocks explains why domestic output falls and foreign output increases in the long

\footnotetext{
${ }^{17}$ This result is also reinforced, of course, by the opposite behavior of foreign firms.
} 
run. The latter results should be interpreted as increased consumption of leisure by domestic residents and reduced consumption of leisure by foreigners, stemming from changes in lifetime wealth. The effect of the increase in net foreign assets showed in Figure 6 is strong enough to counterbalance the negative wealth effects for domestic agents, deriving form the fact that, in the long run as well as in the short-run, they will have to pay taxes to finance the fiscal expansion. The effects of changes in $\eta$ on long-run output showed in Figures 3 and 4 are consistent with the intuition that output moves mainly in response to the accumulation of net foreign assets in the periods in which prices are flexible: for domestic residents a higher $\eta$ implies higher net foreign assets, and therefore a reduced labour supply in the long run (and viceversa for foreign residents). 


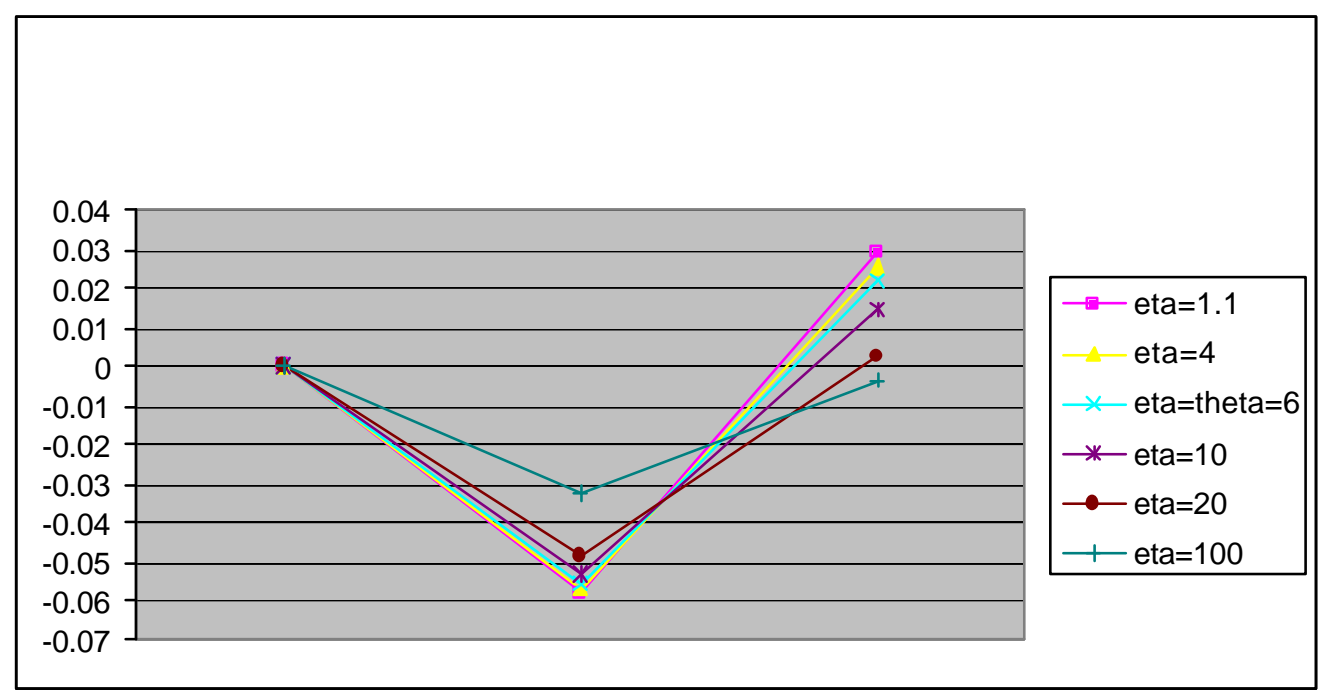

Figure 1: Effect of a Domestic Fiscal Shock on Domestic Private Consumption: Benchmark Case

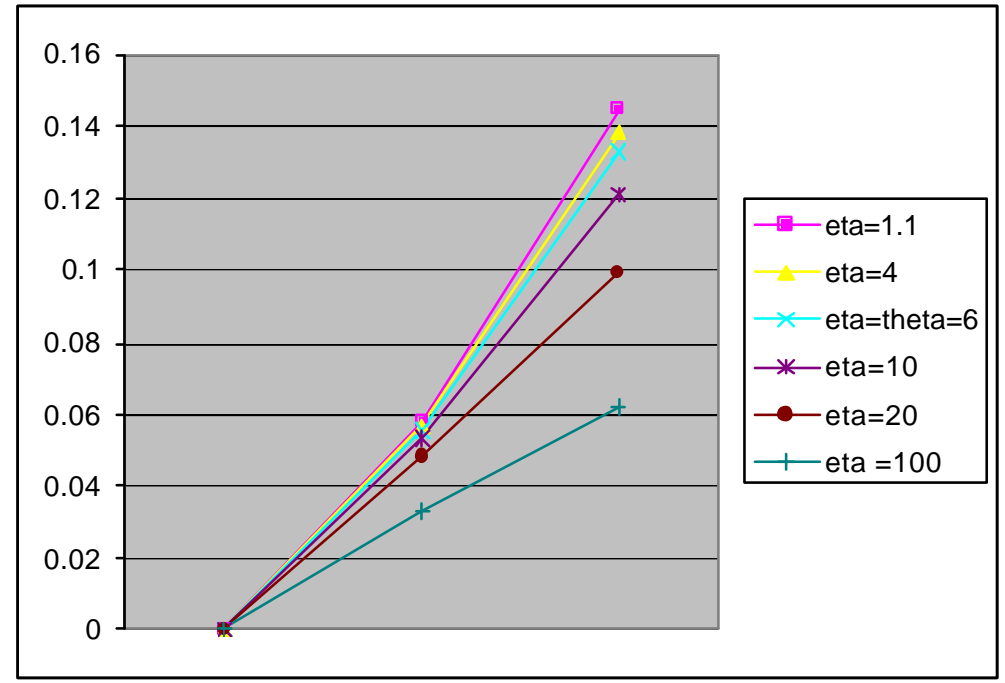

Figure 2: Effect of a Domestic Fiscal Shock on Foreign Private Consumption: Benchmark Case. 


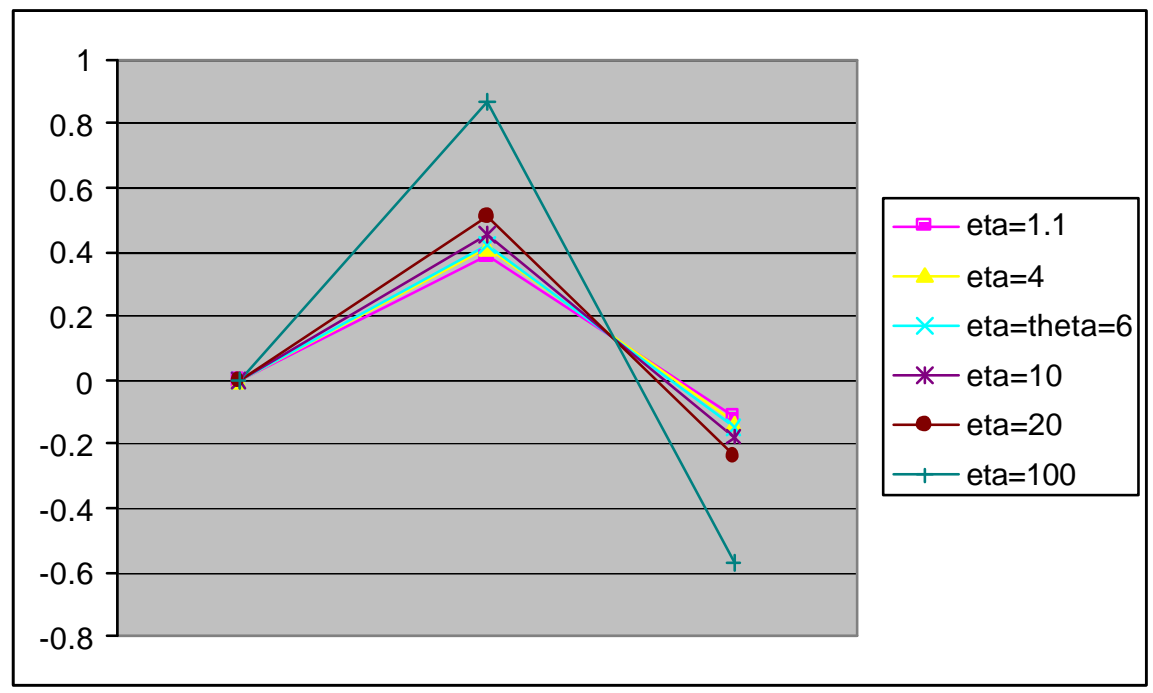

Figure 3: Effects of a Domestic Fiscal Shock on Domestic Output: Benchmark Case

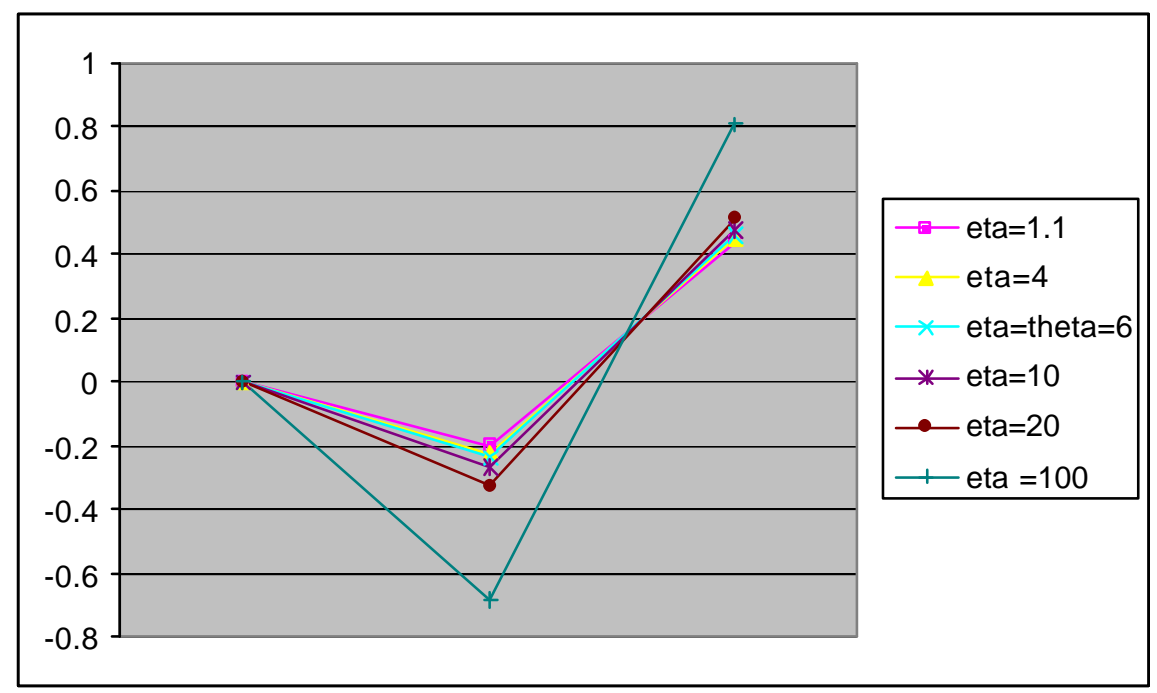

Figure 4: Effects of a Domestic Fiscal Shock on Foreign Output: Benchmark Case 


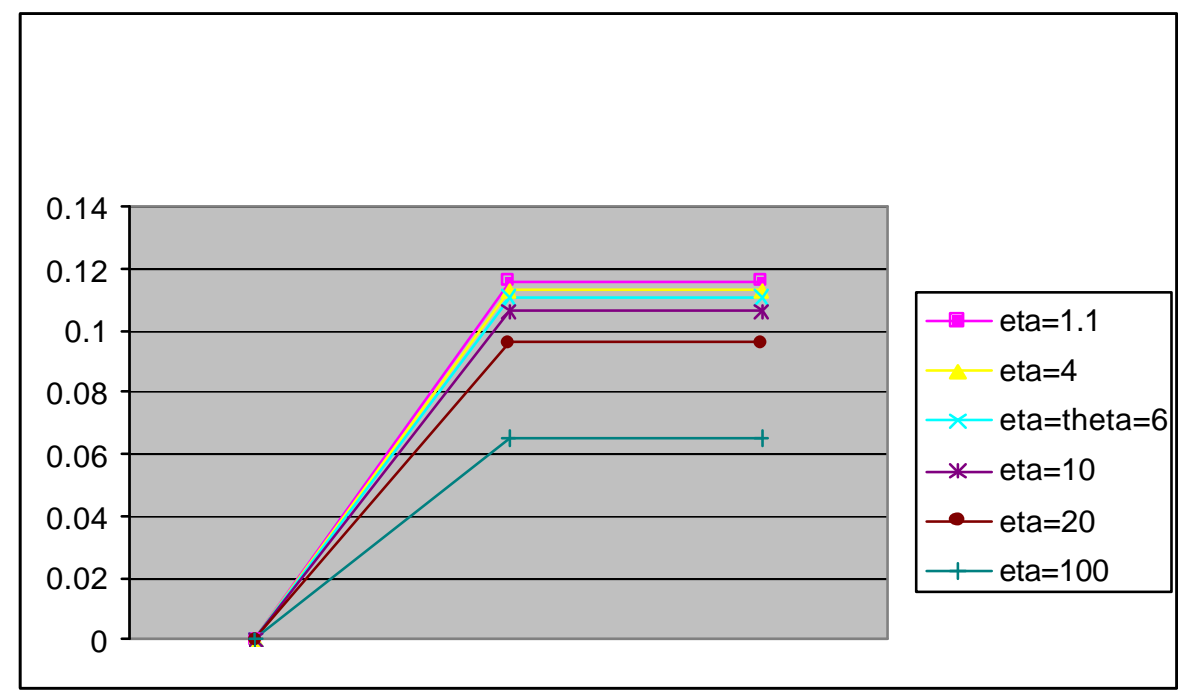

Figure 5: Effects of a Domestic Fiscal Shock on the Exchange Rate: Benchmark Case

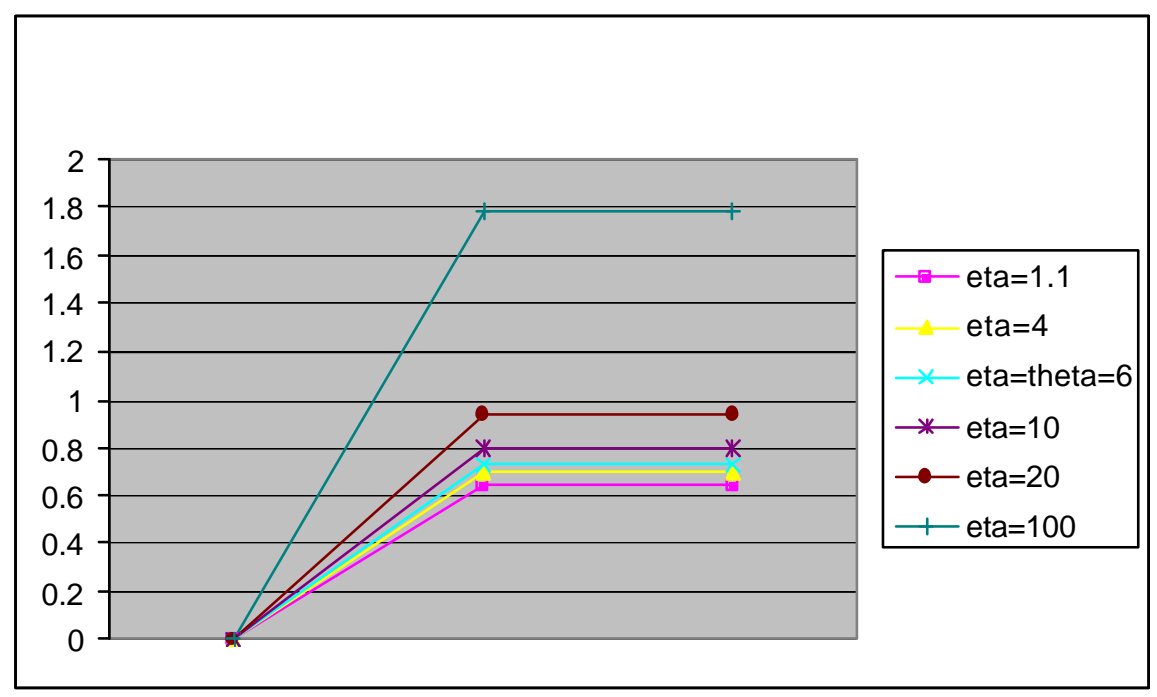

Figure 6: Effects of a Domestic Fiscal Shock on Net Foreign Assets Held by Domestic Residents: Benchmark Case 


\subsection{Sensitivity Experiments}

In our sensitivity experiments (not reported here for reason of space) we have considered the cases of a low discount factor $(\beta=.9)$, of a high initial public to private spending ratio $(\lambda=.46)$ and of a smaller and larger dimension of the domestic country relative to the foreign $(n=.1$ and $n=.9$ respectively). The macroeconomic interdependence pattern following a domestic fiscal shock is, in any of the above case, qualitatively similar to the one that the model displays in the benchmark case, even though there are obviously differences in the magnitudes of some effects. Similarly, the effects of public competition policies (increases in $\eta$ ) always work in the some direction as in the benchmark case, giving some reassurance that the results presented in 3.3 do not depend on the particular parametrization chosen.

\section{Welfare Effects}

Obstfeld and Rogoff (1995) have emphasized how taking output as an indicator of welfare can be misleading in an open economy, in which output and consumption movements are not necessarily correlated. Furthermore, with an endogenous labour supply the welfare enhancing role of leisure time also needs to be taken in to account. One of the main advantages of using a microfounded framework is the possibility to carry out normative analysis based on a rigorous welfare metric.

This is particularly useful for our analysis, since the positive effects of fiscal policy shocks and of public competition policies (increases in $\eta$ ) discussed in the previous section have divergent welfare implications. The reduction in domestic private consumption relative to foreign and the increase in shortrun relative output (i.e. reduction in relative leisure), for example, imply a reduction in domestic welfare compared to foreign welfare. In the long run, on the other hand, domestic output falls and foreign output increases following a domestic fiscal shock. The increase in leisure associate with these long-run output movements could counterbalance the negative effect deriving from the reduction in relative consumption. The implication of increasing 
$\eta$ are also not clear if they are not added up together in a welfare metric. A higher $\eta$, for example, makes the response of domestic consumption less negative in the short-run but reduces the positive consumption response in the long run (see Figure 1), with contrasting effects on welfare.

In Table 2 we report the overall welfare changes both in the domestic and in the foreign countries following a domestic fiscal shock, for the different values of $\eta$ considered in our experiments in section 3. As customary in this literature, we assume that the welfare effects of changes in real balances are negligible and we focus on changes in the real components of the utility function (1). The values reported in Table 2 are calculated as follows

$$
\text { welfare }=\frac{d U^{R}}{U_{S S}^{R}}
$$

where $U_{S S}^{R}$ is lifetime real utility calculated at the initial pre-shock steady state and $d U^{R}$ is obtained by totally differentiating (1). Taking in to account that the new steady is reached in the period after the shock, we have

$$
d U^{R}=\widetilde{c}-k Y_{S S}^{2} \widetilde{y}+\frac{1}{\delta}\left(\widehat{c}-k Y_{S S}^{2} \widehat{y}\right)
$$

The welfare effects reported in Table 2 correspond to a parametrization equal to the one used for the benchmark case simulations, and a value of $k=.1$.

Table 2: Welfare Effects of a Domestic Fiscal Shock

\begin{tabular}{|l|l|l|}
\hline & Home & Foreign \\
\hline$\eta=1.1$ & 0.25 & -0.59 \\
\hline$\eta=4$ & 0.29 & -0.65 \\
\hline$\eta=\theta=6$ & 0.32 & -0.70 \\
\hline$\eta=10$ & 0.37 & -0.77 \\
\hline$\eta=20$ & 0.50 & -0.93 \\
\hline$\eta=100$ & 1.35 & -1.84 \\
\hline
\end{tabular}

Table 2 shows that the overall welfare effect of a domestic fiscal shock is positive for the domestic country and negative for the foreign country. This numerical example suggests that the long run-gains in leisure enjoyed by the domestic country relative to the foreign can more than offset the decrease in relative consumption. Table 2 also shows that increasing $\eta$ unambiguously magnifies the results, increasing the positive response of domestic welfare and the negative response of foreign welfare. The implementation of public competition policies has an overall positive effect on domestic utility because 
the reduced fall in short-run consumption and the increased leisure in the long run more than offset the negative utility deriving from such policies, like the fall in long-run consumption and the increase in short run output. For the foreign country, the opposite is true. ${ }^{18}$

The findings that overall home agents gain and foreigners lose when the domestic country expands contrasts with Obstfeld and Rogoff claim that "overall Foreign benefits and Home loses when Home's government spends more." (Obstfeld and Rogoff, 1996 pag. 706). While this is undoubtedly true if we only take in to account relative consumption movements, our analysis shows that Obstfeld and Rogoff's (1996) conclusion does not necessarily carries on to our model for realistic parameters values. Furthermore, increases in $\eta$ are likely to widen the welfare differential between the two countries.

\section{Conclusions}

In this paper we have focused on the positive and normative implications of public competition policies in presence of asymmetric fiscal shocks. Our results suggest that the implementation of such policies can significantly affect the macroeconomic interdependence pattern that follows fiscal expansions.

In welfare terms, public competition policies tend to widen the gap between country that expands and the other country. Another way of interpreting our results is that countries with a larger government sector should have an incentive to promote the implementation of global structural reforms of public spending management, such as the ones that we have represented in the paper by an increase in the price elasticity of substitution of public consumption.

\footnotetext{
${ }^{18}$ The same qualitative welfare results are also obtained in most of the case considered for the sensitivity analysis, with the exception of the fact that, when the domestic country is very big $(n=.9)$, the overall effect on domestic welfare can actually be negative, while an increase in $\eta$ still has a positive effect on the utility response even in this case. See appendix for welfare evaluations in the sensitivity analysis.
} 
Appendix

A1). Parameters values

$\psi_{1}=\frac{\theta-1}{\theta-1+\lambda(\eta-1)}-\frac{\theta}{\theta+\lambda \eta}$

$\psi_{2}=\frac{\lambda(\eta-1)}{\theta-1+\lambda(\eta-1)}-\frac{\lambda \eta}{\theta+\lambda \eta}$

$\psi_{3}=\frac{\theta(\theta-1)}{\theta-1+\lambda(\eta-1)}+\frac{\lambda \eta(\eta-1)}{\theta-1+\lambda(\eta-1)}-\frac{\theta^{2}}{\theta+\lambda \eta}-\frac{\lambda \eta^{2}}{\theta+\lambda \eta}$

\section{References}

[1] Blanchard, O.J. and N. Kiyotaki, 1987, "Monopolistic Competition and the Effects of Aggregate Demand", American Economic Review 77: 647666

[2] Dixon, H. and N. Rankin (1995), The New Macroeconomics: Imperfect Markets and Policy Effectiveness, Cambridge: Cambridge University Press.

[3] Duggan, M. (2002), "Does Contracting Out Increase the Efficiency of Government Programs? Evidence from Medicaid HMOs", NBER Working Paper No. w9091.

[4] Finn, M.G., 1998, "Cyclical Effects of Government's Employment and Goods Purchases", International Economic Review 39: 635-657.

[5] Gali, J., (1994), "Monopolistic Competition, Business Cycles and the Composition of Aggregate Demand," Journal of Economic Theory 63, 73-96.

[6] Ganelli, G. (2003), "Useful Government Spending, Direct Crowding-Out and Fiscal Policy Interdependence", Journal of International Money and Finance 22 (1), pp 87-103.

[7] Ganelli, G. and P. R. Lane (2002), "Dynamic General Equilibrium Analysis: The Open Economy Dimension", CEPR DP 3540. Forthcoming in Elements in Dynamic Macroeconomic Analysis (S. Altug, J. Chadha, C. Nolan, eds), Cambridge University Press. 
[8] Obstfeld, M. and K. Rogoff, (1995) "Exchange Rate Dynamics Redux", Journal of Political Economy 103, pp. 624-660.

[9] Obstfeld, M. and K. Rogoff, (1996), Foundations of International Macroeconomics (Ch 10) Cambridge, MA: MIT Press.

[10] Rotemberg, J. and Woodford, M. (1992) "Oligopolistic Pricing and the Effects of Aggregate Demand on Economic Activity" Journal of Political Economy Vol. 100, pp. 1153-1207

[11] Sutherland A., (1996), "Financial Market Integration and Macroeconomic Volatility", Scandinavian Journal of Economics 98: 521-539. 